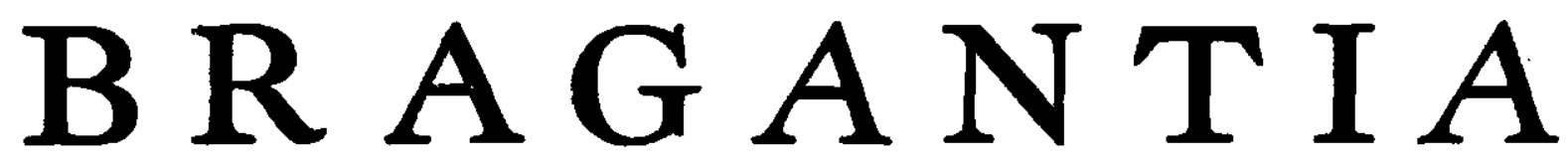

Boletim Técnico da Divisão de Experimentação e Pesquisas I N S TITUTO A GRONÔMICO

\begin{tabular}{lll}
\hline \hline Vol. 10 & Campinas, Setembro de 1950 & N. \\
\hline \hline
\end{tabular}

\title{
QUANTIDADE DE ĀGUA TRANSPIRADA PELO CAFEEIRO CULTIVADO AO SOL
}

Coaraci M. Franco e Romeu Inforzato, engenheiros agrónomos, Secção de Fisiologia e Alimentação das Plantas, Instituto Agronômico de Campinas

\section{1 - INTRODUÇÃO}

O estudo da transpiração das plantas interessa à agronomia sob diversos aspectos. $O$ conhecimento, pelo menos aproximado, da quantidade de água retirada do solo, pela transpiração da planta, é uma necessidade básica na elaboração de projetos de irrigação. No caso do cafeeiro (Coffea arabica L.), êste Instituto já iniciou estudos agronômicos sôbre a irrigação desta cultura. Pelos resultados preliminares e pela situação atual da lavoura, tudo indica que a irrigação dos cafèzais se desenvolverá grandemente em futuro próximo. Há, pois, interêsse em estudos visando a determinação da quantidade de água transpirada pelo cafeeiro, em condições de cultura. Além disto, para o prosseguimento dos trabalhos sôbre o sombreamento dos cafèzais em andamento na Secção de Fisiologia é de grande valor oconhecimento aproximado da quantidade de água retirada do solo pelo cafeeiro e pela árvore de sombra.

Convém lembrar que nenhum dos métodos existentes para a medida da transpiração das plantas satisfaz plenamente, quando se trata de medir a transpiração in loco, nas condições de cultura. Todos são mais ou menos falhos e sujeitos à crítica. Devido a isso e também ao fato de serem tantos e tão variáveis os fatôres que influem sôbre a quantidade de água retirada do solo por uma cultura, os resultados obtidos de estudos desta natureza não devem ser tomados como exatos, mas, apenas, como indicadores da ordem de grandeza do fenômeno.

Neste trabalho tratamos da medida da quantidade de água transpirada pelo cafeeiro cultivado ao sol, em todos os meses do ano.

\section{2 - MÉTODOS}

\section{1 - PESAGEM RÃPIDA DAS FÔLHAS}

Inicialmente, tentamos empregar o método de pesagem rápida das fôlhas, id ealizado por Pfaff (3) e melhorado por Hüber (5) e que Rawitscher (4) já empregou em fôlhas de cafeeiro. Este método baseia-se no fato consta- 
tado pelos seus atores de qur na matoria das plantas uma folha, quando destacada, continua transpirando durante alguns minutos, na mesma razão (jue o fazia quando ainda prêsa à planta. Por isso, para a determinaģão da transpiração por êste método, a fôlha é destacada, prêsa verticalmente a um dos braços de uma balanģa especial, sensível, e pesada de minuto em minuto, durante algum tempo. As perdas de pêso observadas nos primeiros minutos devem ser constantes ou variar pouro em tôrno de un valor médio dando, nesse caso, a medida da transpiração da fôlha. Determinando-se a área da fôlha, podc-se calcular fàcilmente a transpiração por unidade de superfície folhar, por minuto. Repetindo-se essa determinação c'm muitas fôlhas colhidas de diferentes partes da planta, sujeitas a diferentes exposições, obter-sc-á um valor médio para a transpiração da planta. A maior vantagem apontada para êste método é a de se poder trabalhar com plantas adultas, nas condições naturais da cultura.

Para a aplicação segura dêste método, é impreseindivel que as perdas de pesso da fôlha nos primeiros minutos sejam poueo variáveis indicando, assim, que a transpiração não foi alterada logo após ser a fôlha destacada de planta.

Aplicando êste método ao cafceiro não verificamos as condições acima descritas. As perdas de pêso da fôlha, em carla minuto, variaram muito a. partir do momento em que ela foi destacada da planta. Fm vista disso, resolvemos investigar se havia movimentos dos estomatos imediatamente após o corte do pecíolo. Para isso, com um porômetro, fizemos várias determinações de porosidade, nas fôlhas em estudo, a curtos intervalos de tempo, até obtenção de valores constantes. Obtidos êstes, cortamos cuidadosamonte o pecíolo isolando, assim, a fôlha do galho. Fm tôd as fôthas estudadas, a porosidade aumentou bastante logo após o corte do pectolo, até atingir um valor máximo, por volta do oitavo minuto, a contal do corte du fôlha. Após atingir êsse valor máximo, observou-se um decréscimo contínuo da porosidade, que prosseguin até o fechamento completo dos estômitos.

1 figura 1 mostra a ocorrência dêsse fenômeno nas fôlhas do cafeeiro ; nẫo se trata, porém, do uma descoberta nova, pois já foi observado em outas plantas, primeiramente por Jarwin (i) e posteriormente por outros autores, dentre os guais Laidlaw o Knight (3). Vurias cuusas tem sirlo sugeridas para explicar a abertum temporária dos estomatos logo apos o corte do pexolo. Duas nos ptrecem mais prováveis. A primeira, sugerida por Darwin (1), é a de que as cólulas epidérmicas perdem água mais ràpidamento do que as células guardas o rue faz com que diminua a pressão exercida por ¿iquelas sobre estas. A consogüentia divto ó a abertura dos cstômatos que se focharão logo após, devido à perda de água também das células guardas. A segunda é a de Dixon (2), de acôrdo com a qual o corte do pecíolo, eliminando ou diminuindo a tensão sob a cual a água so acha na fôlha, faz com gre ela aflue em maior quantidade nos células cstomáticas, que então se ternam mais túrgidas ocasionando a maior abertura dos estômatos. Como : cumntidude do água existente nos vasos folhares ó pequena, em poucos minutos é conoumida, e os estomator se fecham definitivamente. 


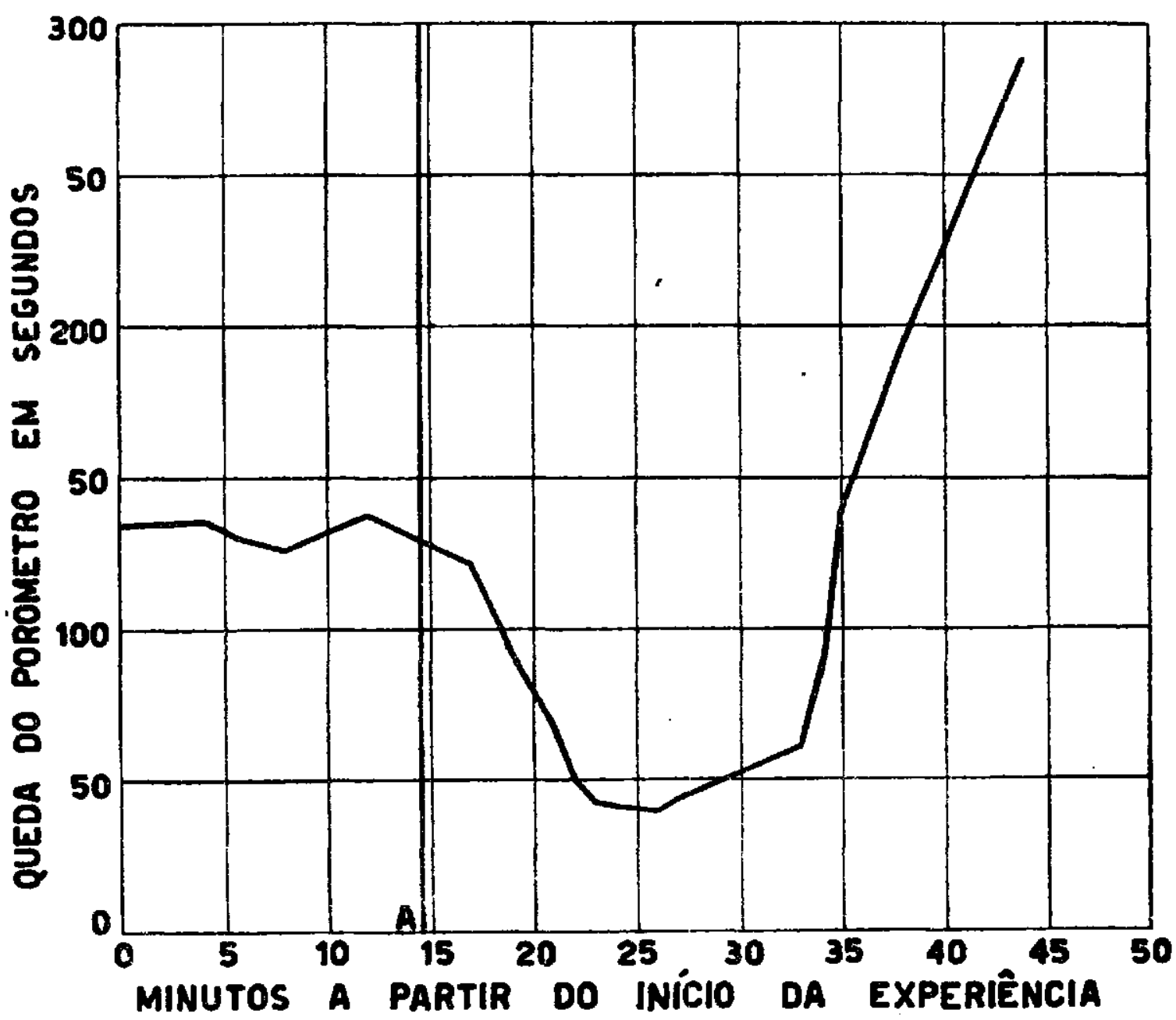

Figura 1.-Marcha da abertura dos estômatos da fôlha do cafeeiro após o corte do pecíolo. $A-$ Momento em que foi cortado o pecíolo.

Esta ocorrência desaconselha o emprêgo do método das pesagens rápidas nos estudos da transpiração do cafeeiro, motivo que nos levou a empregar o método do qual trataremos a seguir.

\section{2-MÉTODO DA PESAGEM DA PLANTA EM VASO}

Trinta e três vasos cilíndricos, de chapa, medindo $50 \mathrm{~cm}$ de altura por $36 \mathrm{~cm}$ de diâmetro (cêrca de 51 litros de capacidade) foram cheios com terra, do tipo roxa misturada, recebendo ainda cada um dêles 1.800 gramas de estêrco de curral. Os vasos não possuíam orifício no fundo para escoamento do excesso de água e foram anteriormente pintados com zarcão, recebendo na parte externa duas demãos de tinta de alumínio sôbre o zarcão, a fim de atenuar o aquecimento pelos raios solares. Em cada vaso, exceto três, foi plantada uma muda de cafeeiro da variedade bourbon - Coffea arabica L. var. bourbon (B. Rodr.) Choussy - com treze meses e meio de idade. Os três vasos que não receberam plantas serviram para o contrôle da perda de água do solo por evaporação. Os vasos foram instalados sôbre vagonetes, os quais eram recolhidos à estufa, à tarde, e retirados para o pátio, 
pela manhã. Quando chovia, as plantas permaneciam na estufa. Os vasos com as plantas que estavam servindo para determinação da transpiração, foram protegidos, em volta, por lâminas de celotex, a fim de evitar a incidência do sol sôbre êles, bem como o aquecimento do solo. Como não poderiam, sem prejuízo para as plantas, permanecer trinta dias hermèticamente fechados, sua superfície foi coberta com uma tampa de celotex, feita em duas metades, deixando, quando colocadas no vaso, um orifício para o tronco. Os três vasos testemunhas para o contrôle da evaporação direta pela superfície do solo, receberam tampas idênticas e, no local destinado ao tronco, foi colocada uma haste de madeira, a fim de imitar as condições reinantes nos vasos com plantas. Foram ainda colocados no meio das outras plantas, a fim de ficarem em condições semelhantes de ambiente. Além disso, a superfície do solo de todos os vasos, inclusive os testemunhas, foi coberta com uma camada de cêrca de dois centímetros de palha de arroz. Isto ajudou a evitar perdas maiores por evaporação e também que as regas danificassem a superfície da terra, expondo as raízes mais superficiais.

Em agôsto de 1949, quando as plantas tinham quase três anos de idade, iniciou-se a medição da transpiração diária. Os vasos foram pesados tôdas as manhãs, para conhecimento da quantidade de água perdida e da umidade do solo. Aos domingos, os vasos não foram pesados. A perda de pesos observada na segunda-feira representa, portanto, a transpiração de dois dias. Como é necessário determinar-se, no fïm do ensaio, a superfície folhar da planta, seria difícil trabalhar durante um ano todo com os mesmos cafeeiros, pois que no fím dêsse tempo a superfície folhar estaria muito aumentada. Foram utilizadas três plantas em cada mês, findo o qual tôdas as fôlhas eram colhidas para a determinação da superfície folhar pelo método dos recortes em papel. Sendo o cafeeiro uma planta de cres: mento bastante lento, a superfície folhar não aumenta sensivelmente $\mathrm{cm}$ trinta dias. Por falta de número suficiente de vasos, foram empregadas, excepcionalmente, as mesmas três plantas durante o período de abril a junho e outras três, no período de junho a agôsto. Nestes casos, a superfície folhar das plantas foi determinada no fim do segundo mês.

Desde que a água é pràticamente imóvel no solo quando sua umidade se acha abaixo do limite água capilar máxima ( ${ }^{1}$, não é possível, com regas controladas, conservar-se a umidade da terra, no interior de um vaso, em um nível determinado de umidade, abaixo daquele limite. As regas foram por isso feitas quando a umidade no interior dos vasos atingia valores próximos da água inativa $\left({ }^{2}\right)$ e a quantidade de água colocada em cada vaso foi a necessária para elevar a umidade de todo o solo nêle contido ao nível da "água capilar máxima."

Para o contrôle da umidade no vaso, deduzimos matemàticamente a seguinte fórmula:

(1) Água capilar máxima é a percentagem máxima de água que o solo retén em condições de drenagem perfeita.

(2) Água inativa é a percentagem de água que o solo ainda encerra quando as plantas dêle não mais conseguem absorver água e murcham definitivamente. 


$$
x=\frac{P\left(p-p^{\prime}\right)}{100-p}, \text { onde }
$$

$x=$ quantidade de água a ser adicionada

$p=$ percentagem de umidade que se quer obter

$P=$ pêso da terra contida no vaso

$p^{\prime}=$ percentagem de umidade do solo ao ser determinado $P$.

A determinação de $P$ foi feita na véspera de se dar início às pesagens. Para isso, deduziu-se, do pêso total do vaso com a planta, o pêso aproximado desta e o do vaso vazio, que é conhecido. Para a determinação de $p$, retiramos do interior do vaso uma pequena amostra de solo, com o auxílio de uma sonda. Como a umidade do solo no interior do vaso está sempre entre a água inativa e a água capilar máxima, fazendo-se $p$ igual à água capilar máxima, $x$ será positivo e indicará a quantidade de água a ser adicionada para se elevar a umidade do solo ao nível da água capilar máxima. Fazendo-se $p$ igual à água inativa, $x$ será negativo e indicará a quantidade de água que o vaso deverá perder para o solo atingir o nível da água inativa. Somando-se o valor de $x$ ao pêso total do vaso no primeiro caso e subtraindo-se no segundo, obtém-se o pêso do vaso, quando a umidade do solo no seu interior se acha no teor água capilar máxima ou no da água inativa, respectivamente, o que possibilita o contrôle perfeito das regas. Para maior clareza, exemplifiquemos: Seja de 50.000 gramas o pêso total do vaso. Digamos que fazendo $p=$ água capilar máxima encontramos $x=4.500$ gramas. Esta é a quantidade de água que deverá ser adicionada ao vaso para se elevar a umidade da terra em seu interior ao nível da água capilar máxima.

Fazendo $p=$ água inativa encontramos, por exemplo, $x=-6.200$. Isto indica que a terra do vaso deverá perder ainda 6.200 gramas de água para que a sua umidade atinja o nível água inativa.

O pêso total do vaso quando a sua umidade estiver no nível água capilar máxima será, portanto: $50.000+4.500=54.500$ gramas. Quando a sua umidade estiver no nível água inativa, o seu pêso será : $50.000-6.200=$ $=43.800$ gramas.

No exemplo acima, o vaso deveria receber água quando o seu pêso se estivesse aproximando de 43.800 gramas e a quantidade de água então adicionada deveria ser a suficiente para elevar o pêso total do vaso a 54.500 gramas.

\section{3 -SUPERFÍCIE FOLHAR DA PLANTA ADUI ${ }^{\top}$ A}

Nos campos de cultura de café da Estação Experimental Central, de Campinas, em terra roxa misturada, foram escolhidos sete cafeeiros com desenvolvimento médio, com cêrca de 40 anos e representativos do estado geral da cultura. Essa escolha foi feita no fim da estação das águas, 
quando as plantas se apresentavam bem enfolhadas. De cada cafeeiro foram colhidas e pesadas tôdas as fôlhas. Logo a seguir, retirou-se, ao acaso, uma amostra de 150 fôlhas, a qual foi também pesada. A superfície dessa amostra foi determinada pelo método dos recortes em papel, calculando-se depois a superfície folhar total de cada planta.

Foram os seguintes os resultados obtidos:

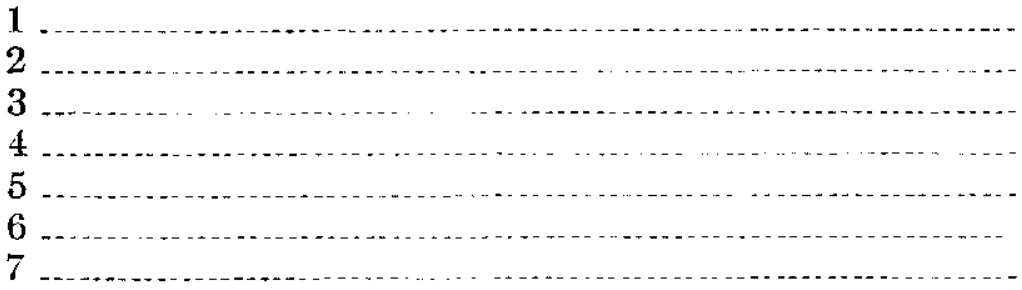

Média

$34,16 \mathrm{~m}^{2}$
$30,64 \mathrm{~m}^{2}$
$27,80 \mathrm{~m}^{2}$
$24,88 \mathrm{~m}^{2}$
$22,87 \mathrm{~m}^{2}$
$34,17 \mathrm{~m}^{2}$
$45,74 \mathrm{~m}^{2}$
$31,46 \mathrm{~m}^{2}$

$34,16 \mathrm{~m}^{2}$

$30,64 \mathrm{~m}^{2}$

$27,80 \mathrm{~m}^{2}$

$22,87 \mathrm{~m}^{2}$

$34,17 \mathrm{~m}^{2}$

$31,46 \mathrm{~m}^{2}$

As fôlhas do cafeciro têm estômatos apenas na face inferior. Nos cálculos da superfície folhar consideramos apenas a superfícic de uma das faces das fôlhas.

\section{4 - RESCITADOS OBTIDOS}

Conhecida a quantidade de água transpirada diàriamente pelos cafeeiros nos vasos e a superfície folhar dessas plantas, calculamos a transpiração média, para cada dia, em $\mathrm{g} / \mathrm{dm}^{2}$ de fôlha. Multiplicando êsse valor por 3.146, que é a superfície folhar em decímetros quadrados, encontrada para a planta de desenvolvimento médio na cultura, determina-se, aproximadamente, a quantidade de água que essa planta deveria retirar do solo, diàriamente, pela transpiração. Simples somas dêsses dados fornecem a quantidade de água que deveria ser transpirada, em cada mês, durante o ano.

O quadro 1 mostra os resultados de transpiração encontrados mensalmente para um cafèzal plantado no espaçamento de 3,5 x 3,5 metros, expressos de diferentes maneiras, ao lado das normais pluviométricas.

Nas condições de cultura, os caleeiros sofrem falta de água por ocasião da estação sêca e êsse é o principal fator da queda de fôlhas observada naquela época.

Em nossa experiência, a terra nos vasos foi mantida sempre com umidade disponivel às plantas, nunca tendo estas sofrido falta de água. Nestas condições, as plantas transpiraram livremente durante o ano todo. Nossos resultados mostram, portanto, aproximadamente, a quantidade de água que um cafeeiro de desenvolvimento médio, nas condições da cultura da Estação Experimental Central de Campinas, deve transpirar cm condiȩões ótimas de água no solo. Aliás, êstes dados são os que mais interessam aos trabalhos de irrigação e também aos estudos sôbre a concorrência em água que as árvores de sombra fazem aos cafeeiros. 
Quadro 1.- Transpiração do cafeeiro e normais pluviométricas nos diversos meses do ano

\begin{tabular}{|c|c|c|c|c|c|}
\hline \multirow[b]{2}{*}{ Mês } & \multicolumn{4}{|c|}{ Transpiração do cafeeiro } & \multirow[b]{2}{*}{$\begin{array}{l}\text { Normal plu- } \\
\text { viométrica } \\
\text { de Campinas } \\
\text { (em } 60 \text { snos) }\end{array}$} \\
\hline & $\begin{array}{l}\text { Equivalên- } \\
\text { cia em que- } \\
\text { da pluvio- } \\
\text { métrica (1) }\end{array}$ & $\begin{array}{c}\text { Por } \\
\text { superficie } \\
\text { folhar }\end{array}$ & Por planta & Por área & \\
\hline & $m m$ & $g / d m^{2}$ & litros & $m^{3} / h a$ & $m m$ \\
\hline Janeiro & 50 & 193,4 & 608 & 496 & 244,6 \\
\hline Fevereiro & 41 & 159,2 & 501 & 409 & 203.9 \\
\hline Marco & 51 & 198,7 & 625 & 510 & 149,3 \\
\hline Abril . & 50 & 196,2 & 617 & 504 & 60,4 \\
\hline Maio ...... & 53 & 206,8 & 651 & 531 & 50,7 \\
\hline Junho & 36 & 139,3 & 438 & 357 & 48,9 \\
\hline Julho & 39 & 151,7 & 487 & 389 & 28,0 \\
\hline Agôsto . ...... & 46 & 180,0 & 566 & 462 & 34,3 \\
\hline Setembro & 56 & 218,2 & 686 & 560 & 71,3 \\
\hline Outubro & 56 & 219,0 & 689 & 562 & 116,1 \\
\hline Novembro... & 63 & 246,0 & 774 & 632 & 155,6 \\
\hline Dezembro & 52 & 203,3 & 640 & 522 & 228,2 \\
\hline Total & 593 & 2311,9 & 7273 & 5935 & 1391,3 \\
\hline
\end{tabular}

(1) Considerando-se um espaçamento de $3,50 \times 3,50$ metros.

$\mathrm{Na}$ figura 2 estão representadas as quedas pluviométricas dos meses em que se determinou a transpiração, as normais pluviométricas e a quantidade de água retirada do solo pela transpiração dos cafeeiros, por hectare, em condições ótimas de água no solo.

Como o trabalho foi executado de agôsto de 1949 ao mesmo mês do ano seguinte, a queda pluviométrica dos meses que vão de agôsto a dezembro se refere ao ano de 1949 , ao passo que a queda pluviométrica dos outros meses corresponde a 1950.

Para o cálculo da transpiração diária, por unidade de superfície, consideramos os totais da transpiração e da superfície folhar das três plantas, em vasos, isto é, dividimos a soma da transpiração dos três cafceiros pela soma da superfície folhar. A transpiração diária média encontrada foi de $6,29 \mathrm{~g} / \mathrm{dm}^{2} /$ dia.

Como a transpiração noturna é desprezível, comparada com a grande quantidade de água transpirada durante as horas de sol, podemos, sem incorrer em grande êrro, considerar o dia de 12 horas para calcular, aproximadamente, a razão de transpiração nas horas de luz. Podemos, assim, comparar a transpiração máxima diária por nós observada, neste trabalho, com outros dados conhecidos. No dia de mais intensa transpiração no decorrer da experiência, a razão diária foi de 17,6 miligramas, por decímetro quadrado e por minuto. Há já vários anos medimos a transpiração de alguns cafeeiros durante uns poucos dias pelo mesmo método empregado neste trabalho. Encontramos, $\mathrm{em}$ um dia quente e de sol intenso, 


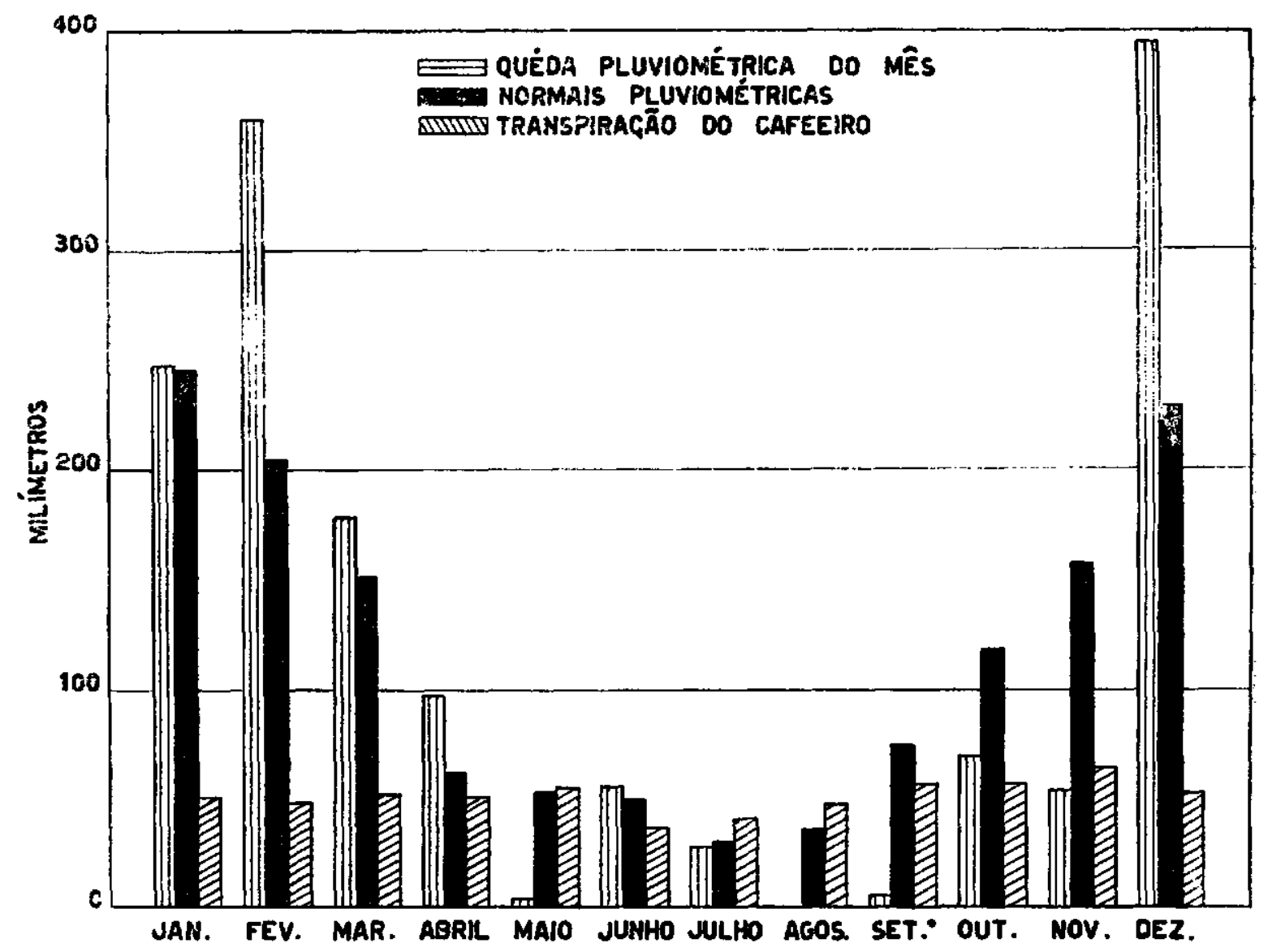

Frgura 2.-Quantidade de água transpirada mensalmente pelo cafeeiro, em comparação com a queda pluviométrica, em Campinas, Estado de São Paulo.

a razão de transpiração diária de $18,2 \mathrm{mg} / \mathrm{dm}^{2} / \mathrm{m}$, para as horas de sol. Nutman (2), trabalhando na África, encontrou uma razão diária máxima para o cafeeiro de $20,67 \mathrm{mg} / \mathrm{dm}^{2} / \mathrm{m}$ também para as horas de sol. Esses três resultados estão muito próximos uns dos outros, indicando que a maior razão diária de transpiração do cafeeiro, em dias de bastante calor e luz, anda ao redor de $20 \mathrm{mg} / \mathrm{dm}^{2} / \mathrm{m}$.

\section{5 - DISCUTSSÕES E CONCLUUSÕES}

No quadro 1 e na figura 2 , as normais pluviométricas são médias de sessenta anos de observações, ao passo que os dados referentes à transpiração são de um único ano. As variações da transpiração são, entretanto, muito menores do que as encontradas no regime pluviométrico. É de se esperar que as variações da transpiração, nos mesmos meses de uma série de anos, sejam bem menores do que as encontradas entre os diferentes meses de um mesmo ano. Isto porque os fatôres climatológicos que mais influem sôbre a transpiração variam muito menos nos mesmos meses de ano para ano do que entre os diferentes meses de um mesmo ano. Além disto, a simples vista da figura 2 mostra não haver correlação entre a queda 
pluviométrica mensal e a quantidade de água transpirada, desde que não haja falta de água no solo.

Do acima exposto, conclui-se que devemos esperar apenas uma pequena variação nos dados de transpiração de um ano para outro e, portanto, os dados obtidos devem estar próximos das médias que se obteriam se se tivesse determinado a transpiração durante uma longa série de anos.

Vemos pelo quadro 1 e figura 2 que, em média, há grande excesso de chuva sôbre a transpiração nos meses que vão de outubro a março. Em abril, junho e setembro, o excesso de chuva sôbre a transpiração é pequeno, sendo que em maio, julho e agôsto há, em média, "deficit" de água, isto é, a transpiração excede a queda pluviométrica. Como as quedas pluviométricas mensais variam grandemente de ano para ano, a situação em um determinado ano pode ser bastante diferente daquela que se apresenta na comparação da transpiração com as médias pluviométricas. Isto se observa bem na figura 2, comparando-se, entre si, as colunas correspondentes à transpiração e as que correspondem à queda pluviométrica dos meses em que foi determinada a transpiração. A umidade retida pelo solo na época das chuvas é suficiente para garantir a transpiração normal do cafeeiro durante bastante tempo. $\bar{E}$ por isso que só se notam os efeitos danosos da falta de água quando a estação sêca se prolonga demasiadamente.

Nos cálculos, consideramos apenas a queda pluviométrica e a transpiração. Outros fatôres, entretanto, interferem no balanço de água do solo, sendo os principais : a) evaporação direta de água da superfície do solo; b) a água que escorre quando o terreno é inclinado ; c) transpiração das ervas más; d) água retida pela folhagem das plantas e que se evapora antes mesmo de chegar ao solo.

A evaporação direta, pela superfície do solo, não influi na umidade dêste, abaixo de $30 \mathrm{~cm}$ de profundidade. Isto quer dizer que mesmo no período de sêca as camadas de solo, que estão a profundidades maiores que $30 \mathrm{~cm}$, não perdem água por evaporação, mas, sòmente, através da absorção e transpiração das plantas. A quantidade de água que escorre em consequência do declive do terreno é variável com aquêle declive, o tipo de solo, a espécie cultivada, os tratos culturais e o regime de chuvas. Em um cafèzal plantado em terra roxa com declive de $6,5 \%$, a percentagem de água de chuva que escorre, ao invés de se infiltrar no solo, é, em média, $1,7 \%$ da queda pluviométrica $\left({ }^{1}\right)$. Considerando-se a queda pluviométrica média de Campinas, essa perda seria de $23,6 \mathrm{~mm}$ de chuva, anualmente, em média. Não temos dados sôbre a transpiração das ervas más. $O$ solo deve, entretanto, perder quantidade apreciável de água através da transpiração daquelas plantas, durante os meses de elevada precipitação e calor. Nos meses de sêca, aquela perda deve ser muito pequena, desprezível talvez. Isto porque, tendo, geralmente, as ervas más um sistema radicular superficial, logo que as camadas superficiais de solo se tornam suficientemente sêcas, essas plantas deixam de vegetar, ou, após a carpa, sòmente voltarão a vegetar nos meses de bastante chuva. Finalmente, há a considerar a quantidade de água da chuva que fica retida na folhagem

(1) Dados obtidos e fornecidos pela Seeção de Conservação do Solo do Instituto Agronômico. 
e daí evapora, sem, portanto, atingir o solo. As perdas de água por êste processo são, naturalmente, maiores em regióes onde a queda pluviométrica se dá em chuvas leves e de pequena duração. Em nosso clima, onde a maior parte da queda pluviométrica é constituída por chuvas mais ou menos torrenciais, é de se esperar uma perda muito pequena por evaporação da água retida pela folhagem das plantas.

Como já se mencionou, para o cálculo da quantidade de água retirada do solo pelo cafeeiro, consideramos neste trabalho a superfície folhar de uma planta de desenvolvimento médio no cafèzal da Estação Experimental Central de Campinas. Em outros cafèzais, principalmente sôbre outros tipos de solo, a superfície folhar das plantas pode ser muito diferente. Se se quiser, entretanto, ter uma idéia apenas da quantidade de água retirada do solo pelas plantas de um dado cafèzal, desde que o clima onde êle se ache não seja muito diferente do de Campinas, que aliás representa bem o clima da maior parte do Estado de S. Paulo, isto se poderá conseguir determinando-se a superfície folhar de várias plantas, consideradas como tendo um desenvolvimento médio em relação à cultura. Tomando-se a média dos resultados encontrados (em $\mathrm{dm}^{2}$ ) e multiplicando-os pelos dados do quadro 1, correspondentes à transpiração em gramas por decímetro quadrado de fôlhas $(193,4-159,2$, etc.), obter-se-á a quantidade de água necessária para a transpiração em cada mês do ano e, finalmente, o total anual.

Para se obter a transpiração em milímetros da altura pluviométrica, dever-se-á dividir a quantidade de água transpirada por uma planta pela área de solo por ela ocupada. Admitimos, nas considerações acima, que, sendo o clima semelhante, a transpiração seja proporcional à superfície folhar das plantas desde que estas pertençam à mesma variedade.

Estes cálculos, embora dêem resultados apenas aproximados, poderão ser úteis aos trabalhos sôbre irrigação de cafèzais. Tendo-se uma idéia do consumo de água pelas plantas, tornar-se-ão mais fáceis e exatos os cálculos sôbre a água necessária para as irrigações, diâmetro dos encanamentos, etc.

\section{S U M M A R Y}

In determinations made with a porometer it was verified that the stomatal opening of coffee leaves increases in size immediately after the leaves are detached from the plant (fig. 1). This fact indicates that the method of rapid weighings of detached leaves is not suitable for studies on the transpiration of the coffee plant.

The transpiration of coffee plants has been determined by the weighing potted plant method. Pots with a capacity for 51 liters were used. They were made of galvanized iron plate and had no drainage hole. When the moisture content of the soil approached the wilting point water was added to bring all the soil mass to fiel capacity. In order to avoid oxygen depletion the pots were not sealed. To decrease the direct evaporation at the soil surface a two-centimeter layer of rice hulls was used as mulch, and a celotex cover was placed on top of the pot. Three similar pots with the same type of protection, but without plants were used to measure the direct evaporation from the soil surface. The weight losses of these pots were subtracted from the weight losses of the pots with plants.

Two to three-year old plants of Coffea arabica var. bourbon were used. Three plants were employed each month and after this time their leaves were picked off, and 
the total leaf area was determined. The tests were carried out for a whole year. The transpiration rates were calculated in $\mathrm{g} / \mathrm{dm}^{2} /$ day.

The total leaf area of an adult coffee plant was found to be $3,146 \mathrm{dm}^{2}$ (average of seven trees). Based on this average and on the transpiration rate of the experimental plants it was possible to calculate approximately the amount of water that an adult coffee plant would transpire under the same conditions.

Since the plants submitted to the experiment did not suffer water shortage at any time, the present results show the approximate amount of water lost by the coffee plant under optimal soil-water conditions. The data are presented in table 1. The figure 1 shows the monthly amount of water lost by transpiration in a coffee plantation compared with the monthly rainfall during a year.

The environmental factors that influence plant transpiration vary much less between the same months of different years than between the different months of the same year. Hence the results obtained should not be far from the average that would be obtained if the transpiration had been measured during a number of years.

Comparing the water lost by transpiration of coffee trees with the average rainfall in"Campinas, State of São Paulo, Brazil, it is seen that from October to March rainfall exceeds water consumption. In April, June, and September the excess is small, and in May, July, and August the amount of water transpired exceeds the average rainfall (fig. 2). Since the rainfall distribution is variable, this figure may be different in a given year.

The highest daily rate of transpiration encountered was $17.6 \mathrm{mg} / \mathrm{dm}^{2} / \mathrm{m}$ (over twelve hours). Previous results obtained by the writers showed $18.2 \mathrm{mg} / \mathrm{dm}^{2} / \mathrm{m}$ to be the rate of transpiration in a very sunny and hot day. Nutman working in Africa (2) found a maximum daily rate of $20.67 / \mathrm{dm}^{2} / \mathrm{m}$ (over nine hours). These data are comparable and must represent approximately the maximum rate of transpiration of the coffee plant.

The average daily transpiration encountered was $6.29 \mathrm{~g} / \mathrm{dm}^{2} /$ day and the total amount of water transpired by a coffee tree in one year was found to be 7,273 liters.

\section{LITERATURA CITADA}

1. Darwin, F. IX. Observations on stomata. Phil. Trans. Roy Soc. Bot. 190 : 531621. 1898.

2. Dixon, H. H. Transpiration and the ascent of sap in plants. Memillan's Science Monographs, 1914, p. 124, citado por Laidlaw (3).

3. Laidlaw, C. G. P. and R. C. Knight. A Description of a Recording Porometer and a note on stomatal behavior during wilting. Ann. Bot. $30: 47-56.1916$.

4. Nutman, F. J. Studies of the physiology of Coffea arabica. III. - Transpiration rates of whole trees in relation to natural environmental conditions. Annals of Botany 5 : 59-81. 1941.

5. Pfaff, F. Ueber den Beitrag der Verdunstung einer Eiche waehrend der ganzen Vegetationsperiode. Sitz-Ber. Kgl. bayer. Ak. wiss. Muenchen. 1 : 27. 1870.

6. Rawitscher, F. Problemas de Fitoecologia com considerações especiais sôbre o Brasil Meridional. Bol. da Fac. Filos. Ciências e Letras, Universdiade de S. Paulo 28, série Botânica $3:$ 8-111. 1942.

7. Ueber, B. Transpiration in verschiedener Stammhoehe. Ztschr. f. Bot. 15 : 465601. 1923. 